TITLE:

\title{
A minimally invasive approach for cochlear implantation using a microendoscope.
}

\section{$\operatorname{AUTHOR}(\mathrm{S}):$}

Hiraumi, Harukazu; Yamamoto, Norio; Sakamoto, Tatsunori; Ito, Juichi

\section{CITATION:}

Hiraumi, Harukazu ...[et al]. A minimally invasive approach for cochlear implantation using a microendoscope.. European Archives of Oto-Rhino-Laryngology 2013, 270(2): 477481

\section{ISSUE DATE:}

2013-02

URL:

http://hdl.handle.net/2433/189860

\section{RIGHT:}

The final publication is available at Springer via http://dx.doi.org/10.1007/s00405-012 2004-9; This is not the published version. Please cite only the published version.; この論文 は出版社版でありません。引用の際には出版社版をご確認ご利用ください。 


\section{A Minimally Invasive Approach for Cochlear Implantation Using a}

\section{Microendoscope}

HARUKAZU HIRAUMI, MD, PhD, NORIO YAMAMOTO, MD, PhD, TATSUNORI SAKAMOTO, MD, PhD, JUICHI ITO, MD, PhD

Department of Otolaryngology, Head and Neck Surgery, Graduate School of

Medicine, Kyoto University, Kyoto, Japan

Running Title: Microendoscopic cochlear implantation

Correspondence to:

HARUKAZU HIRAUMI, MD, PhD

Department of Otolaryngology-Head and Neck Surgery,

Graduate School of Medicine, Kyoto University,

Kawaharacho 54, Shogoin, Sakyo-ku, 606-8507 Kyoto, Japan

Tel: +81-75-751-3346 Fax: +81-75-751-7225

E-mail: hhiraumi@ent.kuhp.kyoto-u.ac.jp 
This study was presented at the Sixth International Symposium on Meniere

Disease and Inner Ear Disorders, November 14 - 17, Kyoto, Japan.

This study was supported by a Grant-in-Aid for Young Scientists (B) (No.

21791612) and by a Grant from the Japanese Foundation for Research and

Promotion of Endoscopy.

We do not have a financial relationship with the organization that sponsored the research.

Conflict of Interest: None 


\section{ABSTRACT}

Background: Given the growing need for minimally invasive approaches to cochlear implantation surgery, we chose to examine the safety of a microendoscopic procedure for cochlear implantation. Methods: We performed cochlear implantation surgery on four human temporal bones using a microendoscope and evaluated the safety of the procedure. Results: With a microendoscope, the facial recess was opened and electrodes were inserted into the cochlea. The size of the mastoidectomy ranged from $5 \times 4$ to $7 \times 7 \mathrm{~mm}$. For three of the temporal bones, the surgery was conducted without any damage to the surrounding structures. The chorda tympanic nerve was inadvertently sacrificed in one temporal bone, in which we skipped the identification of the incus. Conclusions: The microendoscope allowed cochlear implantation surgery to be performed with a mastoidectomy of minimal size.

Keywords: cochlear implant, minimally invasive surgery, microendoscope 


\section{INTRODUCTION}

Cochlear implantation is now a widely accepted treatment for profound sensorineural hearing loss. Conventional cochlear implantation surgery is conducted with the facial recess approach, which involves the need for a wide mastoidectomy. The mastoid cell system regulates middle ear pressure ${ }^{1}$. Because the high area-to-volume ratio of the mastoid cell system is important for gas exchange through the mucosa ${ }^{2}$, a wide mastoidectomy may lead to negative middle ear pressure and ear drum retraction. In cochlear implantation patients, this can result in unfavorable conditions, including cholesteatoma formation, middle ear infection, and electrode protrusion. Although some doctors are developing minimally invasive strategies for cochlear implantation surgery utilizing image guidance systems to avoid the need for a wide mastoidectomy ${ }^{3-4}$, these procedures are not yet commonly used. One reason for this is that surgeons are not able to see the surgical field directly. Recently, the use of microendoscopy has been reported to provide direct surgical views and requires only a small ostium ${ }^{5-6}$. However, the potential use of the microendoscope in cochlear implantation surgery has not been evaluated. In this study, we examined the effectiveness 
and safety of microendoscopy for minimally invasive cochlear implantation surgery using human temporal bones.

\section{MATERIALS AND METHODS}

Four human temporal bones with no middle or inner ear diseases were obtained from four individuals (aged from 68 - 76 years at the time of death; all four were male). A commercially available microendoscope designed for the nasolacrimal duct $(0.9 \mathrm{~mm}$ in outer diameter, $50 \mathrm{~mm}$ in length, with the tip bent at an angle of approximately 15 degrees; FiberTech, Tokyo, Japan) was prepared (Figure 1).

The following six steps were used to perform the cochlear implantation: 1) Pre-operative planning was based on a cone-beam computed tomography (CT) scan (Accuitomo, Morita, Japan). A straight line from the cortical bone to the basal turn of the cochlea was drawn on the CT scan (Figure 2-A). A three-dimensional reconstruction of the temporal bone was created, and the approaching line was projected to the cortical bone to determine where to begin drilling. 2) A small mastoidectomy hole (with a diameter of $4 \mathrm{~mm}$ ) was made from the cortical bone to the antrum using a 
conventional drilling system (Figure 2-B). The following procedures were performed using a microendoscope, which was introduced through the hole (Figure 2-C). 3) The attic is opened and the short process of the incus is identified (in this study, the incus was detected in bones $2-4$ ) (Figure 2-D). 4) The facial recess is opened (Figure 2-E); 5) the round window niche is detected through the facial recess, and cochleostomy is performed just ventral to the round window niche (Figure 2-F). 6) Lastly, the electrode (HiRes90K $1 \mathrm{j}$ electrode, AB, USA) is inserted into the cochlea using an inserter (Figure 2-G). Steps $3-6$ were performed using a microendoscope and a microdrill (Skeeter Otologic Drill System, Medtronic, USA). The size of the mastoidectomy was enlarged as necessary during steps $3-6$. All surgical procedures were performed by one author (H.H.).

After the surgery, a CT scan was obtained, and the closest distance from the drilled path to the facial nerve and to the chorda tympani was calculated. The electrode was then removed, and the size of the mastoidectomy was measured along the surface of the temporal bone. Subsequently, the bones were drilled to check for damage to the surrounding structures. After the total mastoidectomy, the size of the posterior 
tympanotomy was measured using an image processing program (ImageJ:

National Institutes of Health, Bethesda, MD, USA).

\section{RESULTS}

In all specimens, the prominence of the lateral semicircular canal was easily identified. In bones $2-4$, the short process of the incus was detected after a transmastoid atticotomy, and a posterior tympanotomy was performed safely. In bone 1, we did not undertake the process of identifying the incus. In this bone, the fallopian canal was opened, which was noted immediately, and severe damage to the facial nerve was avoided. However, the chorda tympani was inadvertently sacrificed. In bones $2-4$, we opened the attic and detected the short process of the incus. In these bones, the fallopian canal and the chorda tympani were preserved. After opening the facial recess, the round window niche was easily detected, and a cochleostomy was performed. The intra-operative findings for bone 4 are shown in Figure 3. In all bones, the electrodes were fully inserted into the cochlea (Fig. 4). The size of the required mastoidectomy, the size of the posterior tympanotomy, as well as the shortest distances to the facial nerve 
and the chorda tympani are summarized in the Table. The surgical time required was about ninety minutes.

\section{DISCUSSION}

In this study, we demonstrate that cochlear implantation using a microendoscope is possible and requires only a small mastoidectomy. The view provided by the microendoscope was sufficient to identify important landmarks while performing cochlear implantation. The handpiece of the microendoscope is quite small, and the tip is bent by 15 degrees, which minimizes the interaction between the microendoscope and other surgical instruments. These characteristics of the microendoscope allow minimally invasive cochlear implantation surgery to be performed under direct visualization.

Cochlear implantation surgery with minimal bone drilling has been explored for years. Kiratzidis et al. reported the usefulness of the trans-canal wall approach ${ }^{7}$. With this approach, the authors created a tunnel through the cortical bone to the facial recess using a specially developed perforator. However, this technique is performed without direct visualization. Recently, 
some authors have applied image guidance systems to minimally invasive cochlear implantation surgery. Majdani et al. succeeded in performing a cochleostomy in human cadavers through a narrow single-channel mastoidotomy with a navigation system ${ }^{4}$. Labadie et al. 8 applied stereotactic techniques to cochlear implantation surgery and showed that this method precisely identified the line from the cortical bone to the cochlea through the facial recess. While these image guidance systems "visualize" the surgical path, they do not guarantee the accuracy required for ear surgery ${ }^{9-10}$. In contrast, microendoscope-based cochlear implantation surgery provides a direct surgical view. We were able to detect surgical landmarks directly and complete the surgery using the same processes as those used in the conventional facial recess approach.

However, to apply this surgery to actual patients, there are some problems that need to be addressed. For one, the resolution of the microendoscope is not as high as that of the microscope. Furthermore, the view obtained with the microendoscope is two-dimensional, and it is distorted at the marginal area. Another problem is the surgical time. In this study, the surgical time was considerably longer than the time required for conventional surgery, 
which resulted from the low power of the microdrill and fogging of the microendoscope lens. These two points are problematic, especially in children. In small children, the area between the facial nerve and chorda tympani is small, and highly accurate procedures are needed. In addition, a surgical procedure with a short duration and minimal bleeding is required. Other potential limitations include a poorly pneumatized mastoid. In such patients, large amounts of bone must be removed, which results in a protracted surgical time. It is likely that the development of new devices specialized for microendoscopic cochlear implantation will resolve these problems. Another option to overcome these problems is the combination of microendoscopy and use of an image guidance system. The image guidance systems provide information about temporal bone anatomy during the surgery, which enhances the accuracy of microendoscopic cochlear implantation. This also enables us to use a powerful conventional drilling system during the early stages of the operation. The effectiveness of the combination of these two technologies should be explored. 


\section{CONCLUSION}

This study demonstrates that the use of a microendoscope allows cochlear implantation surgery to be performed with a minimally sized mastoidectomy. The view provided by the microendoscope is sufficient to detect important landmarks, which allows for the safe execution of the facial recess approach. Microendoscopy may be applied to minimally invasive cochlear implantation in combination with other currently available technologies.

\section{ACKNOWLEDGEMENTS}

This study was supported by a Grant-in-Aid for Young Scientists (B) (No. 21791612) and by a grant from the Japanese Foundation for Research and Promotion of Endoscopy.

\section{CONFLICT OF INTEREST}

We do not have a financial relationship with the organization that sponsored this research. 


\section{References}

1. Takahashi H, Sugimaru T, Honjo I, et al. Assessment of the gas exchange function of the middle ear using nitrous oxide. A preliminary study. Acta Otolaryngol 1994;114:643-6.

2. Magnuson B. Functions of the mastoid cell system: auto-regulation of temperature and gas pressure. J Laryngol Otol 2003;117:99-103.

3. Labadie RF, Balachandran R, Mitchell JE, et al. Clinical validation study of percutaneous cochlear access using patient-customized microstereotactic frames. Otol Neurotol 2010;31:94-9.

4. Majdani O, Bartling SH, Leinung M, et al. A true minimally invasive approach for cochlear implantation: high accuracy in cranial base navigation through flat-panel-based volume computed tomography. Otol Neurotol 2008;29:120-3.

5. Hiraumi H, Nakagawa T, Ito J. Efficiency of a transtympanic approach to the round window membrane using a microendoscope. Eur Arch Otorhinolaryngol 2009;266:367-71.

6. Plontke SK, Plinkert PK, Plinkert B, Koitschev A, Zenner HP, Lowenheim H. Transtympanic endoscopy for drug delivery to the inner ear using a new microendoscope. Adv Otorhinolaryngol 2002;59:149-55.

7. Kiratzidis T, Arnold W, Iliades T. Veria operation updated. I. The trans-canal wall cochlear implantation. ORL J Otorhinolaryngol Relat Spec 2002;64:406-12.

8. Labadie RF, Noble JH, Dawant BM, Balachandran R, Majdani O, Fitzpatrick JM. Clinical validation of percutaneous cochlear implant surgery: initial report. Laryngoscope 2008;118:1031-9.

9. Grauvogel TD, Soteriou E, Metzger MC, Berlis A, Maier W. Influence of different registration modalities on navigation accuracy in ear, nose, and throat surgery depending on the surgical field. Laryngoscope 2010;120:881-8.

10. Grayeli AB, Esquia-Medina G, Nguyen Y, et al. Use of anatomic or invasive markers in association with skin surface registration in image-guided surgery of the temporal bone. Acta Otolaryngol 2009;129:405-10. 


\section{Figure Legends}

\section{Figure 1}

A microendoscope for the nasolacrimal duct (FiberTech, Tokyo, Japan). The outer diameter is $0.9 \mathrm{~mm}$, and the length is $50 \mathrm{~mm}$. The tip is bent approximately 15 degrees. The view angle is 70 degrees.

\section{Figure 2}

Illustrations of the surgical procedure. A straight line from the cortical bone to the basal turn of the cochlea via the antrum and the facial recess was drawn on the CT scan to determine where to start drilling (A). A small mastoidectomy was made using a conventional drilling system (B). The microendoscope and microdrill were introduced into the antrum (C). The attic was opened, and the short process of the incus was identified (D). The facial recess was opened (E). The microendoscope and microdrill were inserted through the facial recess, and a cochleostomy was performed (F). The electrode was inserted into the cochlea using an inserter (G). 


\section{Figure 3}

Surgical views from the microendoscopic cochlear implantation surgery performed on bone 4. (A) The prominence of the lateral semicircular canal (arrowhead) and (B) the short process of the incus (arrow) were observed. (C) The facial recess was opened (arrow). (D) The incuido-stapedial joint (arrow), and the chorda tympani (arrowhead) are visible. (E) The round window niche (arrow) was detected (arrowhead: the incuido-stapedial joint). (F) The cochlea was opened (arrow).

\section{Figure 4}

The CT image taken after the electrode was fully inserted into the cochlea of bone 4 . 

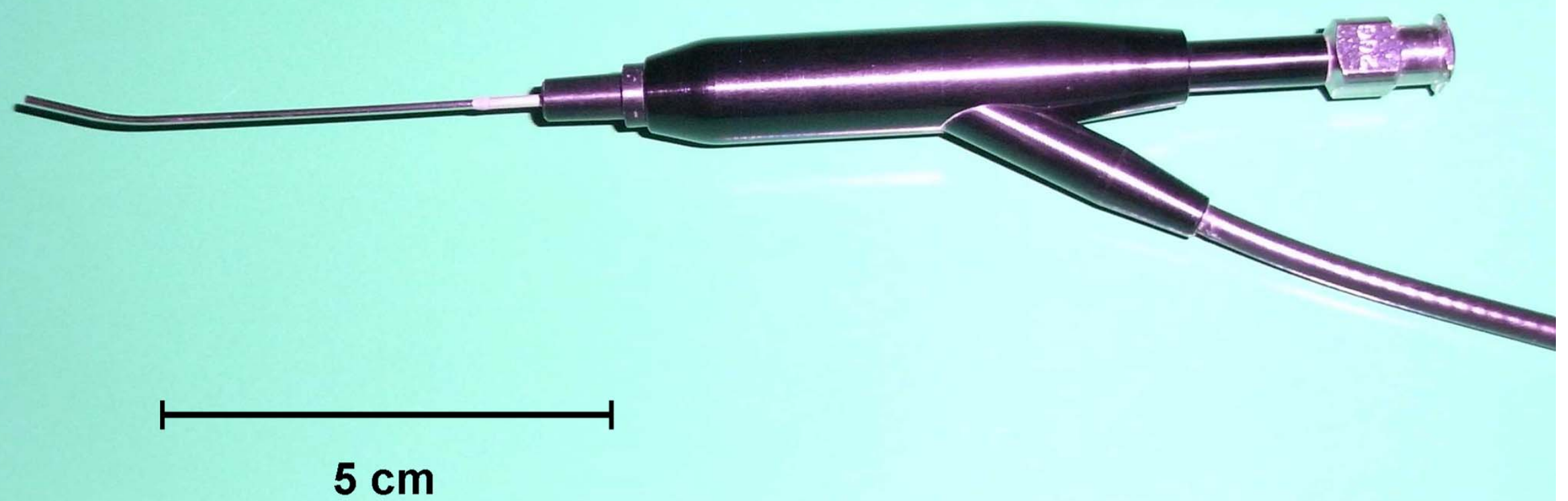

Figure 1 

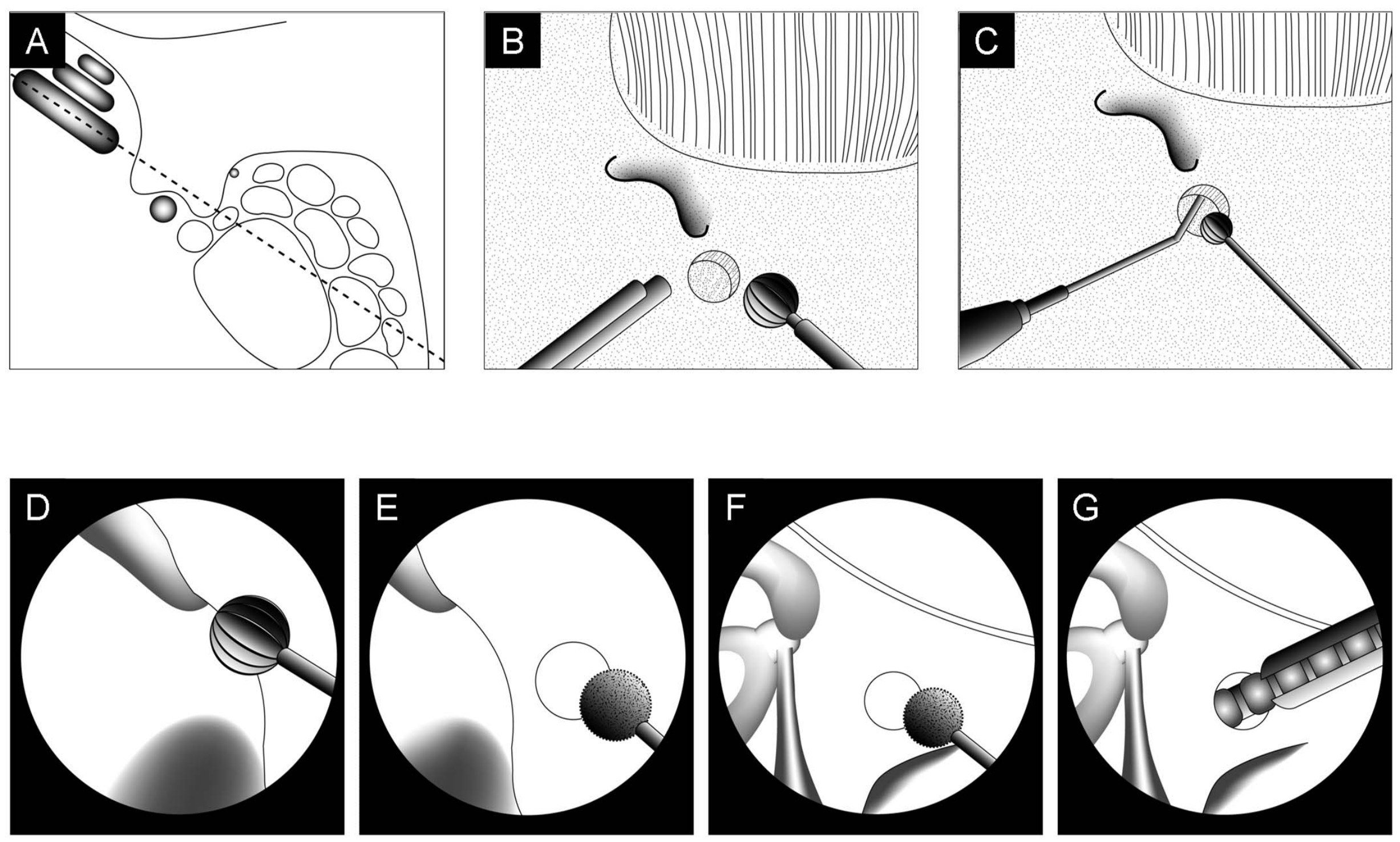

Figure 2 

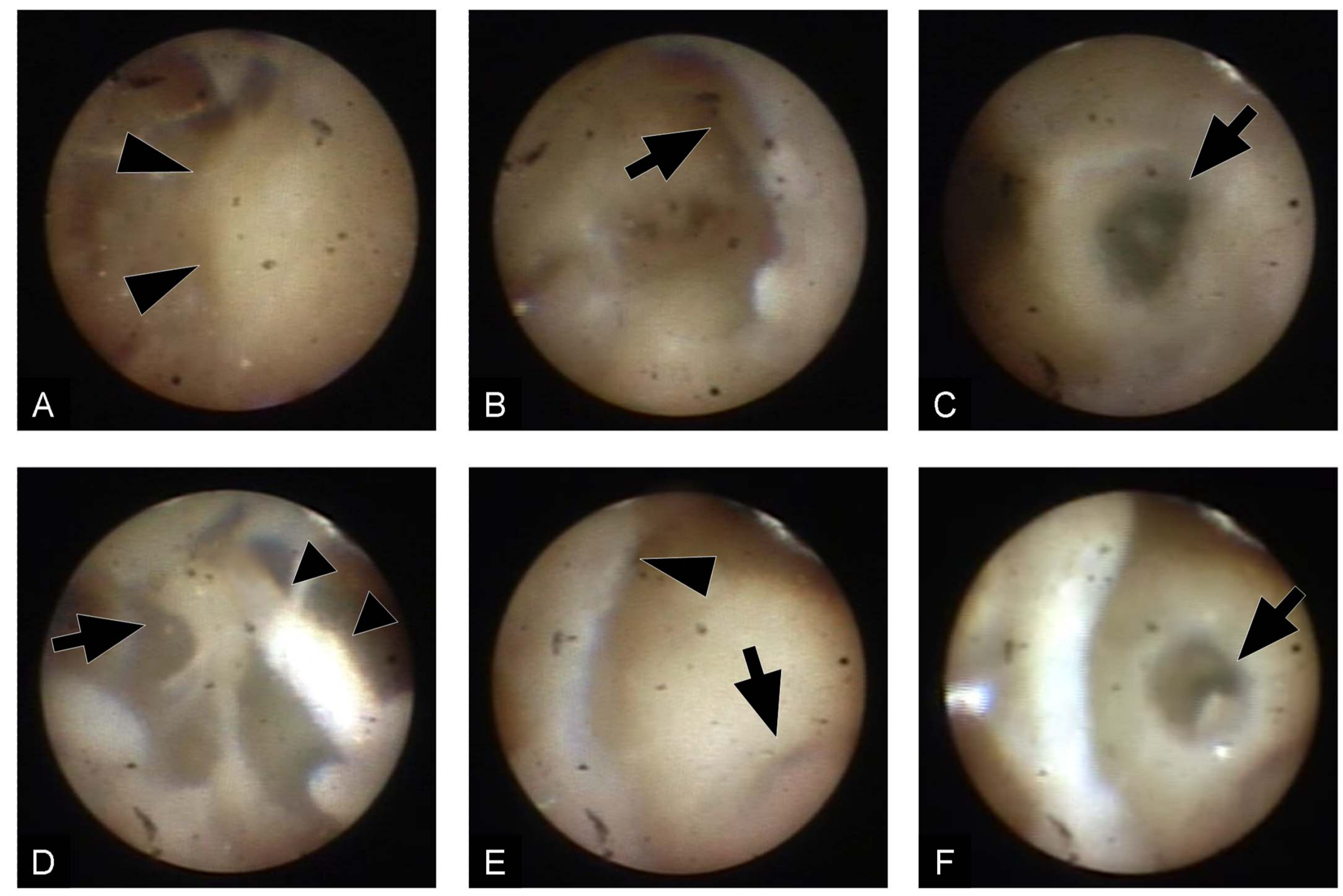

Figure 3 


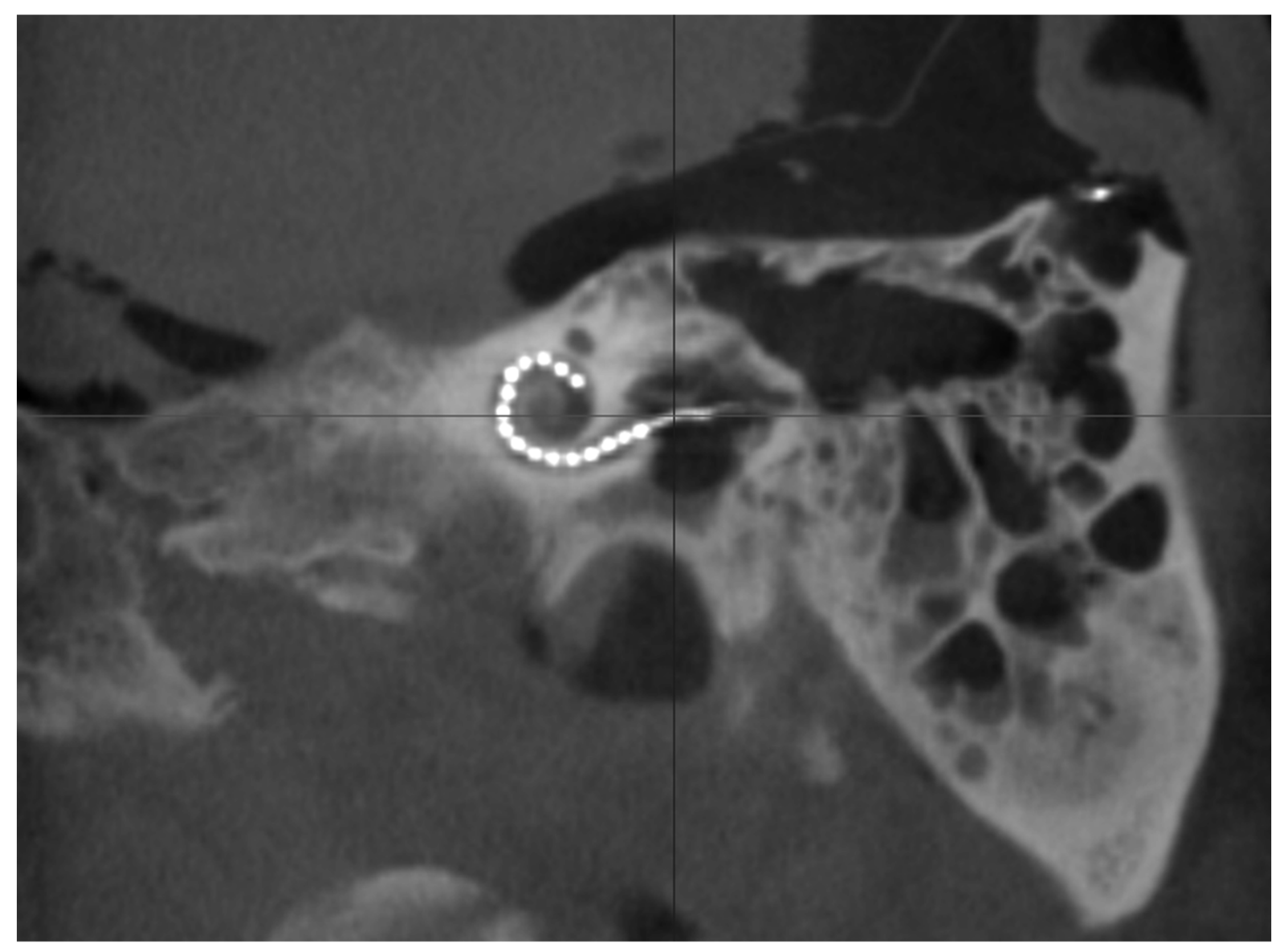

Figure 4 
Table

\begin{tabular}{|l|l|l|l|l|l|}
\hline & & $\begin{array}{l}\text { Size of the } \\
\text { mastoidectomy } \\
(\mathrm{mm})\end{array}$ & $\begin{array}{l}\text { Size of the } \\
\text { posterior } \\
\text { hypotympanotomy } \\
(\mathrm{mm})\end{array}$ & $\begin{array}{l}\text { Distance to } \\
\text { the facial } \\
\text { nerve }(\mathrm{mm})\end{array}$ & $\begin{array}{l}\text { Distance to } \\
\text { the chorda } \\
\text { tympani } \\
(\mathrm{mm})\end{array}$ \\
\hline 1 & $\mathrm{Lt}$ & $7 \times 7$ & $2.4 \times 3.7$ & 0.0 & 0.0 \\
\hline 2 & $\mathrm{Rt}$ & $7 \times 5$ & $2.1 \times 2.5$ & 0.4 & 0.3 \\
\hline 3 & $\mathrm{Lt}$ & $8 \times 4$ & $2.1 \times 2.9$ & 0.4 & 0.5 \\
\hline 4 & $\mathrm{Rt}$ & $5 \times 4$ & $2.1 \times 2.1$ & 0.8 & 0.7 \\
\hline
\end{tabular}

